\title{
Implied Default Probabilities and Default Recovery Ratios: An Analysis of Argentine Eurobonds $2000-2002$
}

\author{
Jochen R. Andritzky*
}

28th January 2004

\begin{abstract}
This paper calculates implied recovery rates and implied default probabilities in a risk neutral setting for Argentine US-Dollar Eurobonds during the Argentine crisis from 2000 to 2002. In a model which is related to Jarrow and Turnbull (1995), the hazard rate is modelled as risk neutral probability using the Gumbel probability distribution. The results show that implied probabilities roughly take five levels, allowing to cut the time frame analyzed into five periods. The jumps between the levels are associated with rating cuts in most cases. In 2000, the estimated location parameter of the Gumbel distribution makes a default event appear most probable after four to five years. Estimated recovery ratios range from above $50 \%$ in the beginning to an average of $25 \%$ in the end.
\end{abstract}

\section{Introduction and literature review}

Financial crises in the 1990s as in Mexico 1994/1995, Asia 1997, Russia 1998, and Brazil 1999, were closely analyzed. All these crises triggered economic disturbances. In Argentina, a long lasting recession and remaining structural deficits caused the erosion of the public budget. The possibility

\footnotetext{
${ }^{*}$ University of St. Gallen, Swiss Institute of Banking and Finance s/bf, Rosenbergstrasse 52, 9000 St. Gallen - Switzerland, Phone +41 71224 7082, email jochen.andritzky@unisg.ch. I thank Paul Söderlind and Klaus Spremann for many suggestions. I also thank the participants of the session C12 at the annual conference of 2003 of the German Economic Association for the helpful discussion. Comments are welcome. All errors are entirely my own.
} 
that the Republic of Argentina could slip into default on its USD 128 billion public debt was widely foreseen. The IMF approved an aid package in December 2000, even though Argentina was unable to meet the IMF's conditions. However, Argentina received another USD 8 billion package in August 2001, which is in addition to its existing USD 14 billion standby credit line with the IMF. One year later, political turmoils and the lack of further help from multilateral institutions drove Argentina into default.

These events provide the background of this analysis of Argentine Eurobonds. From Eurobond market prices, information about the market expectations can be derived provided risk neutrality is assumed. By applying a pricing model for risky sovereign debt it will be possible to see how investors' expectations change during the period 2000 to 2002.

The theory of pricing credit risk was initially developed for valuing risky corporate debt. A first class of these models is called asset based or structural models. They assume a value process for the firm's underlying assets. The firm defaults when the value of the firm's underlying assets falls below its financial obligations or below an exogenously specified boundary. Debtor's incentive patterns can also be an aspect of the structural models. ${ }^{1}$ This methodology was researched closely by Merton (1974), Black and Cox (1976), Fischer et al. (1989), Hull and White (1995), Longstaff and Schwartz (1995), and others.

A second class of models assumes that the bankruptcy process is specified exogenously. These so called intensity based or reduced form approaches were described by Jarrow and Turnbull (1995), Jarrow et al. (1997), Lando (1998), Duffie and Singleton (1999), and others.

Even if similar approaches for calculating credit risk are applicable, one must carefully consider the differences between risky corporate and risky sovereign debt. Most important, there is no bankruptcy code that protects the holder of sovereign debt in case of default. ${ }^{2}$ Except for foreign assets which could theoretically serve as collateral for foreign debtholders, the sovereign has nothing more to lose than reputation. For this reason governments may consider sovereign default as a political decision. ${ }^{3}$ The following debt restructuring is also subject to strong political influences. ${ }^{4}$

\footnotetext{
${ }^{1}$ For instance, Gibson and Sundaresan (1999) develop a formal model for optimal default strategies for sovereign debt.

${ }^{2}$ This is valid with exception of some basic rules applying in case of default like collective action clauses (CAC) which are common under British Law.

${ }^{3}$ See Eaton and Gersovitz (1981).

${ }^{4}$ From a game theoretic approach, Ghosal and Miller (2002) developed rational choice arguments to bankruptcy proceedings.
} 
This explains the variety of outcomes for sovereign bond investors after default and shows why expectations about the loss given default are important for creditors of risky sovereign claims.

The model used throughout this paper can be characterized as a reduced form model and follows an approach presented in Duffie and Singleton (1999). The underlying tree structure of this model has previously been described in Jarrow and Turnbull (1995) and was already empirically implemented for sovereign bonds by Merrick (2001). ${ }^{5}$ The default intensity is implemented by using a Gumbel probability distribution to derive risk neutral default probabilities. ${ }^{6}$ Assuming this distribution for the time of default is a new feature introduced by this article.

From the application of the model on Argentine bond data the following important results can be derived: The implied default probability parameter shows significant jumps during the sample period. Due to the model specification, the pricing of the short term Eurobonds maturing within six years conveys very valuable information to consistently form the shape of the hazard rate. Implied recovery values are constantly declining but get an intermediate uplift after the USD 40 billion aid package from the IMF arrived. During the last stages of the crisis, the implied recovery ratio seems to be the major driver of Eurobond prices.

The remaining of this paper is structured as follows: Section 2 introduces the pricing methodology of default risk and explains the pricing model applied in this study. An introduction to the estimation methodology is given in Section 3. Section 4 describes the input data. Section 5 estimates daily coefficients and tries to describe the course of crisis in five periods. In Section 6 the pricing of single issues is researched. Section 7 concludes.

\section{The model}

Due to the rare event of sovereign default, quantified measures of default risk hardly exist in literature. Claessens and Pennacchi (1996) derive pseudo default probabilities from Mexican Brady bond prices. Bhanot (1998) analyzes implied default recovery rates of coupon payments for Brady bonds. Keswani (2000) uses the model of Duffie and Singleton (1999) to analyze

\footnotetext{
${ }^{5}$ Merrick (2001) analyzes contagion effects during the Russian public debt crisis in 1998.

${ }^{6}$ Assuming risk neutrality is common in literature. If risk aversion is actually prevailing, the risk neutral default likelihood will be greater than the physical default probability. Analogously, the risk neutral recovery rate is lower than its physical counterpart. See Bakshi et al. (2001).
} 
Figure 1: Event tree

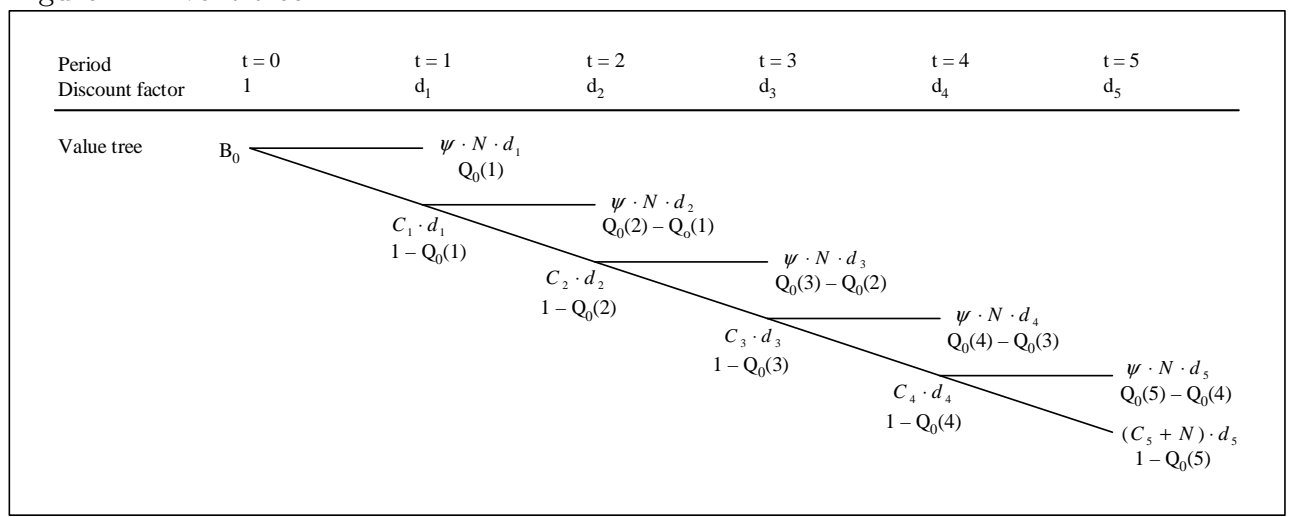

Event tree to determine the value of a five-period bond subject to default risk. $B_{0}$ is the resulting value of the risky bond. $C_{t}$ are coupon payments, $N$ the bond's par value. $\psi$ stands for recovery ratio of the face value $N . d_{t}$ are the risk free discount factors. The cumulative probability of default as seen from $t=0$ is indicated by $Q_{0}(t)$.

Brady bonds. Merrick (2001) compares Russian and Argentine Eurobonds during the Russian crisis 1998.

In this paper, the value of the sovereign Eurobonds is derived from the discounted present value of the coupon payments and the nominal face value in the case that no default occurs. If the bond defaults, the following recovery scheme applies: Coupons are no longer paid, but the investor will receive a fractional recovery of the face value upon default. This follows the common recovery of face value (RFV) formulation and contrasts with Jarrow and Turnbull (1995). ${ }^{7}$

Assuming that investors are risk neutral, all payments are discounted at the risk free rate. The current bond value is calculated from the sum of all discounted payments weighted by their probability of occurrence. This is illustrated in a binomial event tree for an example in discrete time setting in Figure 1.

The example assumes a bond which expires after five periods. The resulting cash flows and their probabilities are marked at each node. All cash flows are multiplied with the discount factor. Discounted cash flows get weighted by their probability. Recovery values are always paid immediately after default. The resulting bond value is $B_{0}$.

Analyzing a cross section of bonds issued by one debtor, the model assumes that there is a joint default probability. This means that the issuer

\footnotetext{
${ }^{7}$ See Bielecki and Rutkowski (2002), p. 34; Cossin and Pirotte (2001), pp. 100f.
} 
can default only on all outstanding bonds at a time. ${ }^{8}$ Analogously, one joint recovery rate for all bonds is assumed. These assumptions are reasonable in the case of Argentina. All bonds in the sample have a covenant of equal coverage which tries to reach maximum equality between the unsecured creditors of different Eurobond issues. There is also no evidence of different bondholder groups which could lead to a different treatment as in the case of Russia where debt issued during the Soviet era takes lower priority than post-Soviet issues. ${ }^{9}$

Modelling the joint default probability can be done in many different ways. Early empirical research applied constant default probabilities where default occurs each period with the same probability. ${ }^{10}$ In this paper an instantaneous hazard rate is used. This way it is possible to embed the model in a time continuous setting along Duffie and Singleton (1999). The hazard rate thereby is the instantaneous probability of default at time $t$ given survival until that time. Let $Q_{t}$ be the cumulative probability of default during the time interval $[0, t]$. The hazard rate as viewed from time 0 is then

$$
\mu_{0}(t) \equiv-\frac{d}{d t} \ln \left(1-Q_{t}\right)
$$

The unconditional probability of default or default function density at a certain point in time $t$ is

$$
\mu(t) e^{-\int_{0}^{t} \mu(s) d s} .
$$

Since payments are not continuous but appear in certain but irregular time intervals, the default probability at payment time $t+\Delta, \Delta \geq 0$, considering the default probability until the last payment date $t$, takes the form

$$
e^{-\int_{0}^{t} \mu(s) d s}\left(1-e^{-\int_{t}^{t+\Delta} \mu(s) d s}\right)=Q_{t+\Delta}-Q_{t} .
$$

In Duffie and Singleton (1999), a constant hazard rate

\footnotetext{
${ }^{8}$ Therefore, Standard \& Poor's created the rating category "selective default (SD)" to account for the possibility that sovereigns may choose to default on only a portion of its total debt.

${ }^{9}$ See Duffie et al. (2003), p. 149.

${ }^{10}$ See Fons (1987), Bhanot (1998). Merrick (2001) uses a linear function of time for the default probability $p$. This approach, even if intuitively appealing, has the disadvantage that if assuming a probability function in the manner of $p_{t}=\alpha+\beta t$, the probability $p_{t}$ can possibly exceed the interval $[0,1]$. A calibration of this model can only be valid within a certain sample of maturities $T \epsilon[t, \tau]$.
} 


$$
\mu(t)=\lambda, \text { with } \lambda \geq 0
$$

is applied as base case. This is a function often applied in modelling default rates. Therefore, the constant hazard rate function will be used in Section 3 to illustrate under which conditions the model can be estimated.

For the empirical analysis of this article, I use a modified hazard function to make the default rate dependent on time. A very convenient function for this purpose is the Gumbel distribution. ${ }^{11}$ The Gumbel probability distribution and its properties are described in Appendix A. Its hazard function is given by

$$
\mu(t)=\frac{1}{\beta} \frac{e^{-(t-\alpha) / \beta}}{e^{e^{-(t-\alpha) / \beta}}-1}
$$

where $\alpha$ is the location parameter and $\beta>0$ is the scale parameter. Analogously to Equation 2 the unconditional probability of default using the Gumbel distribution becomes

$$
\frac{1}{\beta} e^{-(t-\alpha) / \beta} e^{-e^{-(t-\alpha) / \beta}} .
$$

Since the mode of this density is $\alpha$, this allows modelling a default probability term structure which shows a maximum at time $t=\alpha$ and has a standard deviation of $\frac{\pi}{\sqrt{6}} \beta$.

For $t \geq 0$, the conditional default probability between time $t$ and $t+\Delta$ from Equation 3 becomes

$$
Q_{t+\Delta}-Q_{t}= \begin{cases}e^{-e^{-\frac{\Delta-\alpha}{\beta}}} & \text { for } t=0 \\ e^{-e^{-\frac{t+\Delta-\alpha}{\beta}}}-e^{-e^{-\frac{t-\alpha}{\beta}}} & \text { for } t>0\end{cases}
$$

This case differentiation is necessary because the extreme value distribution is defined for negative variates as well. Equation 7 ensures that the survival probability at time $t=0$ is one which implies that $Q_{0}$ must be zero.

Estimating the parameters of the extreme value hazard function offers insight in the expected default risk structure of Argentina. The parameter $\alpha$ roughly indicates at what point in time default was seen as most probable. This unveils important information about a cross section of Argentine Eurobonds with different maturities. Using a bootstrapping method, the

\footnotetext{
${ }^{11}$ See Gumbel (1958).
} 
implied zero curve already indicates that the hazard rate is not constant over time but rather reaches a peak which can be approximated by $\alpha$ using the Gumbel default probability density. At this peak, the cumulative default function $Q(t)$ shows its steepest ascent.

Economically, this makes sense for an economy which passes through a temporary recession. Having bonds in the estimation sample with a short duration, the estimation may get distorted when using a constant hazard function. Such an estimation would underprice bonds with longer duration since it cannot reflect an expected economic recovery. ${ }^{12}$ The Gumbel distribution function, in contrast, can be parameterized in such a way that the hazard rate decreases in the long-run. The scale parameter $\beta$ refines the shape of the default probability density since its standard deviation increases with a growing scale parameter. In other words, the scale parameter determines the slope of the cumulative default function.

These ingredients can now be combined to calculate the value of a risky bond from its constituents which are the coupon payments, the notional payment, and the recovery value. Therefore, imagine a bond with $J$ coupon payments up to maturity at time $t=\tau$. The periodical coupon payments $C_{j}$ are paid at times $t_{j}$ with $j=1, \ldots, J$. The face value $N$ is paid at maturity $\tau$. Discounting these payments back to time $t=0$ using a continuous risk free term structure $r_{t}$, the result would equal the bond value of a risk free claim. The risk neutral value of a risky claim can be obtained by weighting these payments with the probability of survival up to that time and adding the recovery value weighted by the default probability. For different hazard functions $\mu(t)$, the bond model value $B_{0}$ of a risky claim is calculated as follows:

$$
\begin{aligned}
B_{0}= & \sum_{j=1}^{J} C_{j} \exp \left\{-\int_{0}^{t_{j}}\left[r_{s}+\mu(s)\right] d s\right\}+ \\
& N \exp \left\{-\int_{0}^{\tau}\left[r_{s}+\mu(s)\right] d s\right\}+ \\
& \psi N \sum_{j=1}^{J} \exp \left(-\int_{0}^{t_{j}} r_{s} d s\right)\left[\exp \left(-\int_{0}^{t_{j-1}} \mu(s) d s\right)-\exp \left(-\int_{0}^{t_{j}} \mu(s) d s\right)\right]
\end{aligned}
$$

Equation 8 represents the bond model value as the sum of three parts.

\footnotetext{
${ }^{12}$ In the model proposed here, such an overestimation of the default probability may get compensated by higher recovery ratios, so that systematic underpricing for long maturities might not be easily observed from the estimation results.
} 
The first part is the sum of the coupon payments multiplied with the continuous discount factor and the survival probability. The second part is the face value received at maturity. It is discounted with the continuous risk free rate and weighted by its survival probability. The third part is the fraction $\psi$ of the face value $N$, which is discounted with the risk free rate and multiplied with the probability of default. Thereby, default can occur between two payment times $t_{j-1}$ and $t_{j}$.

In general, there are two ways of implementing this equation given a sufficient sample of bond prices and discount factors:

1. Taking a time series of one bond, the three coefficients $\alpha, \beta$, and $\psi$ can be estimated for a single bond as constants during the observation period.

2. In a cross section of bonds sharing the same cross sectional default probabilities, an estimate gives us the three coefficients $\alpha, \beta$, and $\psi$ at any point in time.

In this study, only the latter aspect will be researched. This implies homogenous market expectations for all Argentine Eurobond issues under consideration, whereas expectations are allowed to change from day to day.

\section{Parameter estimation}

Duffie and Singleton (1999) have shown that the bond value can be calculated using the discount rate

$$
R=r+h L
$$

in a recovery of market value (RMV) framework, where $r$ is the continuous risk free rate, $h$ is the hazard rate process and $L$ is the process of fractional loss at default. In such a setting, it is not possible to separate the two parameters in a sample which shares the same hazard process and recovery rate. ${ }^{13}$

This just serves as example where the simultaneous estimation of both default probability and recovery parameters leads to an identification problem. Any model which estimates default and recovery parameters has to deal with this problem, even if different recovery assumptions (for example, recovery of face value or recovery of treasury value) are applied. In any of

\footnotetext{
${ }^{13}$ See Duffie and Singleton (1999), pp. $705 f$.
} 
these cases, an empirical estimation of these parameters for coupon bonds could typically unveil very high positive correlation between the intensity parameter of the hazard process and the recovery parameter.

The following will demonstrate that the bond value model used in this analysis can be considered suitable to estimate both parameters when the data comply to certain characteristics.

Estimates of the implied parameters are obtained by comparing observed dirty bond prices and theoretical bond model values, which are calculated from Equation 8. The root mean squared error (RMSE) - taking the relative pricing error - is calculated as follows:

$$
\sqrt{\frac{1}{n} \sum_{n=1}^{N}\left(\frac{V_{n}-B_{n}}{B_{n}}\right)^{2}}
$$

Thereby, $B_{n}$ is the bond model value of bond $n$ in a cross section with $N$ bonds and $V_{n}$ is its observed dirty price. To gain estimates of the parameters, the RMSE is minimized using an optimization algorithm.

Figure 2 shows the behavior of the model price for bonds with different coupons and maturities using a constant hazard rate as in Equation 4. A constant hazard rate of $\lambda=0.25$ results in a risk neutral default probability of $22 \%$ within the first year, $53 \%$ within three years, and $92 \%$ within ten years. This scenario is very realistic for risky sovereign debt as in the case of Argentina, where high coupon bonds trade well below par even at the beginning of the observation period in 2000 and drop into the price range between USD 60 and USD 70 in summer 2001.

Looking at the curvature of the bond model value of a zero coupon bond, the following observation is obvious. The default probability for longer maturities, that means maturities of more than 15 periods, becomes extremely high, so that the recovery value is the main constituent of the bond value. For shorter maturities, the model value consists to a considerable extent of the bullet amortization weighted by the probability of survival $\left(1-Q_{0}\right)$, which determines the characteristic curvature of the surface in Figure 2 for short maturities.

Of course, different coupons also help to identify the model parameters explicitly. However, the difference in coupons has to be substantial, resulting in distinctively different bond prices. ${ }^{14}$ From this point it appears helpful

\footnotetext{
${ }^{14}$ Unfortunately, this is not always the case. The Argentine Eurobond sample researched in this article contains bonds with a coupon range between $8.375 \%$ and $12.000 \%$; see Table 1.
} 
Figure 2: Bond model value

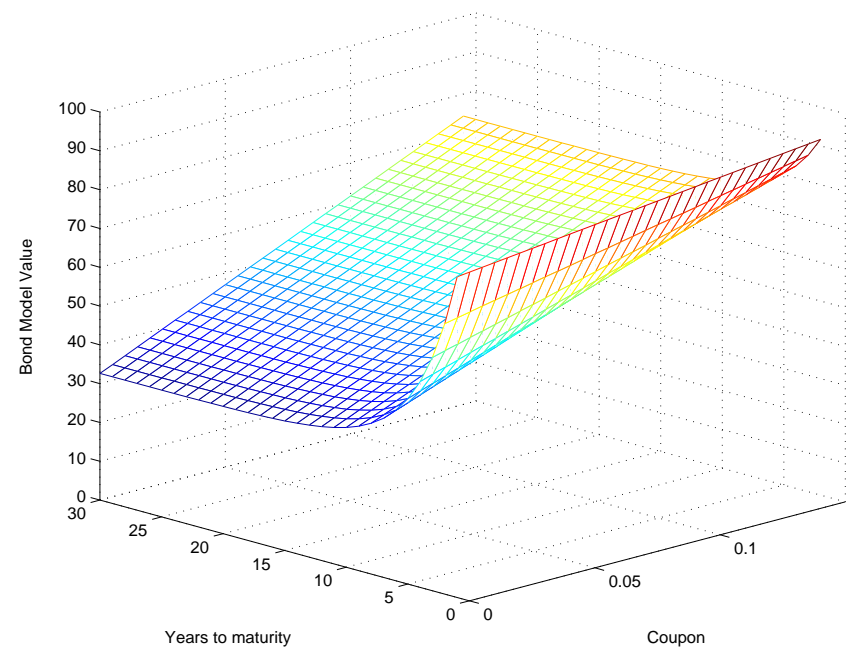

Model value of a coupon bond in dependence of its maturity and coupon rate using a constant hazard rate model. In the figure, a constant hazard rate $\lambda=0.25$ and a recovery ratio $\psi=0.40$ is assumed (see Equations 4 and 8 ). The bond has a face value of 100 and coupons are paid annually. The term structure of risk free interest rates is flat at $5 \%$.

to regard a measure which combines maturity and coupon in one figure. For this reason the Macauley duration is used in the following argumentation.

Imagine a sample of two bonds with high durations, from which market prices are available. Assume that the market participants apply a pricing framework similar to that illustrated in Figure 2. From these two prices one could estimate the implied default parameter $\lambda$ and the recovery ratio $\psi \cdot{ }^{15}$ If there is considerable default risk prevailing, the bonds would trade at almost the same level. This constellation would allow to estimate the recovery ratio $\psi$ with sufficient precision, but it would be difficult to separate the parameter $\lambda$. It is therefore necessary to have one bond in the sample with a shorter maturity.

Figures 3 illustrates the two cases in contour plots of the root mean squared pricing error (see Equation 10). Even if the difference in duration is the same in both plots, a minimization of the RMSE is difficult in the first case. The plot indicates that there is a narrow valley of possible combina-

\footnotetext{
${ }^{15}$ This is achieved by applying a hazard function similar to that in Equation 4 and calculating a bond model value along Equation 8. Taking the market prices and minimizing the resulting RMSE (see Equation 10), one gains estimates of the two parameters $\lambda$ and $\psi$.
} 
Figure 3: RMSE contour plot for two cases
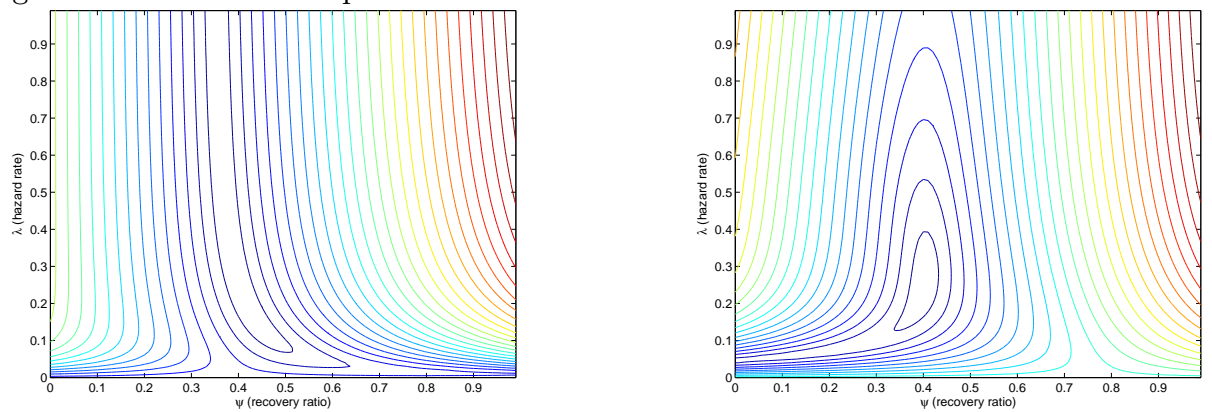

Contour plots of the root mean squared pricing error (see Equation 10) in the constant hazard rate model (see Equation 4). The pricing error is the difference between the bond model value for different parameter values for $\lambda$ and $\psi$ and the simulated prices of two bonds, which are calculated for $\lambda=0.25$ and $\psi=0.40$ (see Equation 8). The term structure of the risk free rate is flat at $5 \%$. The two zero bonds in the left hand figure mature after twenty and thirty periods. In the right hand figure, the bonds mature after one and eleven periods. The contour lines suggest lower levels in the middle of the figures.

tions of $\lambda$ and $\psi$, for which the RMSE is very small. In contrast, the right hand plot clearly hints at a global minimum at $\lambda=0.25$ and $\psi=0.40$.

From this section the following conclusions can be drawn:

- For the determination of the recovery ratio, the bonds in the sample should contain considerable default risk. When the default probability is very low, the recovery value determines only a very small portion of the total bond price, from which it is difficult to identify the recovery parameter accurately.

- To estimate the default parameter, it is important to catch the characteristics of the curvature of the cumulative default probability function $Q_{0}(t)$, be it a constant hazard rate or a Gumbel default probability function. For this purpose the following rule of thumb can be applied: if $D_{h}, h=1, \ldots, H$, is the Macauley duration of the $H$ bonds in the sample, a wide range of different values of the conditional default probability function $\mu\left(D_{h}\right) e^{-\int_{0}^{D_{h}} \mu(s) d s}$ is helpful. ${ }^{16}$

Since the instantaneous default probability is the derivative of the cumulative probability of default $Q_{0}(t)$, its maximum hints at the point in time, where the $Q_{0}(t)$ shows its steepest incline. Cash flows due around this point in time are most heavily affected by the increase of the default probability.

${ }^{16}$ See Equation 2. 
Table 1: Sample of US-Dollar denominated Eurobonds issued by the Republic of Argentina

\begin{tabular}{lrcccccc}
\hline Name & Coupon & $\begin{array}{c}\text { First cou- } \\
\text { pon date }\end{array}$ & $\begin{array}{c}\text { Maturity } \\
\text { date }\end{array}$ & $\begin{array}{c}\text { Par value } \\
(\$ \mathrm{mln})\end{array}$ & \multicolumn{3}{c}{ Price range } \\
Min. & & Mean & Max. \\
\hline Arg01 & $9.250 \%$ & 23-Feb-1996 & 23-Feb-2001 & 1000 & 98.16 & 99.85 & 100.56 \\
Arg03 & $8.375 \%$ & 20-Dec-1993 & 20-Dec-2003 & 1000 & 24.03 & 71.80 & 96.85 \\
Arg06 & $11.000 \%$ & 09-Oct-1996 & 09-Oct-2006 & 1000 & 24.64 & 71.64 & 99.25 \\
Arg09 & $11.750 \%$ & 07-Apr-1999 & 07-Apr-2009 & 1000 & 24.50 & 69.40 & 98.78 \\
Arg10 & $11.375 \%$ & 15-Mar-2000 & 15-Mar-2010 & 1000 & 20.50 & 67.38 & 96.15 \\
Arg15 & $11.750 \%$ & 15-Jun-2000 & 15-Jun-2015 & 2000 & 22.69 & 66.67 & 97.65 \\
Arg17 & $11.375 \%$ & 30-Jan-1997 & 30-Jan-2017 & 4000 & 22.50 & 66.79 & 95.50 \\
Arg20 & $12.000 \%$ & 03-Feb-2000 & 01-Feb-2020 & 1000 & 20.50 & 68.28 & 99.25 \\
Arg27 & $9.750 \%$ & 19-Sep-1997 & 19-Sep-2027 & 2000 & 23.50 & 60.52 & 85.93 \\
\hline All
\end{tabular}

All bonds have semi-annual coupon payments.

However, identification problems may still occur with real market prices. Especially when market prices are very volatile, less liquid issues with sticky prices may distort the estimation. Exceptional market movements can explain most outliers, which show characteristically high RMSE and strong positive correlation between the default and the recovery parameters.

\section{Input data}

The estimation of the parameters requires two sets of data, Argentine Eurobond prices and a risk free term structure. The latter is a necessary ingredient of the bond model function but has a limited impact on the calculations. Since the objective is to quantify sovereign risk, it is not easy to find a proxy for the risk free rate. Here the US Treasury bond yields are accepted as representative for the risk free rate since the United States are the most solvent and most powerful debtor in the world.

To ensure consistency, I will stick to the US Treasury benchmark yields provided by Datastream. This yield is calculated from the constant maturity yield published daily in the Financial Times using linear interpolation. Daily values for this benchmark exist for maturities of two, three, five, seven, ten, and thirty years. For maturities in between, rates are linearly interpolated.

The sample includes all Argentine Eurobonds with bullet amortization for which market prices are available from Datastream. To avoid distortions, three very illiquid issues are excluded from the data sample. They are the Arg19, 12.125\%, maturing 25 February 2019; the Arg30, 10.250\%, maturing 21 July 2030; and the Arg31, 12.000\%, maturing 31 January 2031. These 
Figure 4: Price chart of two Argentine Eurobonds

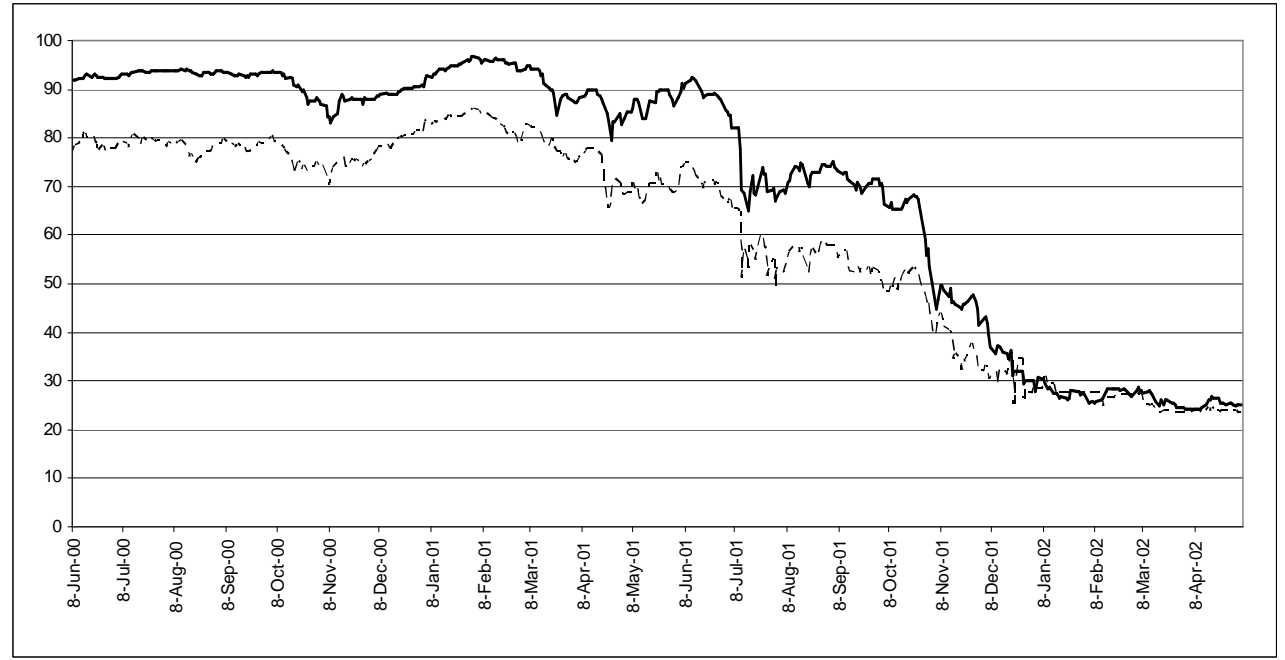

Clean mid prices of the $8.375 \%$ Arg03 (solid line) and the 9.750\% Arg27 bond (dashed line) in USD. Source: Datastream.

issues have an outstanding amount of less than USD 274 million. ${ }^{17}$ Some bonds are also not considered in this sample due to special features like capitalizing coupons et cetera. ${ }^{18}$ This sample adjustment does not have a high impact on the estimation because these bonds are situated in the upper range of maturities. ${ }^{19}$

After these adjustments the sample includes nine US-Dollar denominated Eurobonds issued by the Republic of Argentina as listed in Table 1. All issues have a fixed coupon and a maturity spectrum between one and 27 years. Daily trading values are received from Datastream. ${ }^{20}$ Accrued interest is

\footnotetext{
${ }^{17}$ Excluded is also the Arg00 8.250\% issue, which had a total par value of USD 100 million and already matured in August 2000. The two outstanding zero bonds, which matured in 2000 and 2001, are thinly traded due to their small volume and are not considered in this analysis.

${ }^{18}$ The Arg01, 12.375\%, maturing 21 February 2012, is an unsecured loan not having the negative pledge guarantee of the other issues and is trading significantly higher. Three bonds maturing in 2008, 2018, and 2031 were issued in June 2001 during a mega debt swap of USD 29.5 billion (including one Peso bond maturing in 2008). Even if these issues are the largest Eurobonds by volume, they are not considered here since they had either varying coupons, were sinking funds, or had capitalizing coupons.

${ }^{19}$ As illustrated in Section 3, the long-term maturity bonds will not play an essential role in the parameter estimation for a very risky country like Argentina.

${ }^{20}$ These prices are the last prices obtained from the market each day, and are quoted as mid-prices without any accrued interest.
} 
Table 2: Standard \& Poor's ratings

\begin{tabular}{cc}
\hline Date & New S\&P bond rating \\
\hline Initial rating & $\mathrm{BB}$ \\
14-Nov-2000 & $\mathrm{BB}-$ \\
26-Mar-2001 & $\mathrm{B}+$ \\
08-May-2001 & $\mathrm{B}$ \\
12-Jun-2001 & $\mathrm{B}-$ \\
09-Oct-2001 & $\mathrm{CCC}+$ \\
30-Oct-2001 & $\mathrm{CC}$ \\
19-Nov-2001 & $\mathrm{D}$ \\
\hline
\end{tabular}

Standard \& Poor's long term foreign currency sovereign credit ratings for all issues in the sample. On 07 November 2001, S\&P put its long term local and foreign currency credit rating to "selective default". The Arg-17 bond was rated D on 27 November 2001. Source: Datastream.

calculated using the 30/360 day count convention.

The sample represents a total nominal amount outstanding of about USD 9.06 billion which is an 11\% share of a total of USD 85 billion external public debt. $^{21}$ The time frame in question is 08 June 2000 to 6 May 2002, including data for 498 trading days. Since the short-maturity bonds convey important information, the Arg01 is included in the analysis, even if its last price is quoted on 19- February 2001.

Figure 4 shows the price chart for two selected issues of different maturities in the period from June 2000 to May 2002. The prices of the two issues remain stable until summer 2001, when Standard \& Poor's downgraded the sovereign credit rating. The price chart shows a downward trend which is intensifying around end of October 2001 after downgrades from CCC + to CC. Bond prices stabilize around the beginning of December 2001 on a very low level which is maintained in 2002.

Table 2 gives an overview about Standard \& Poor's ratings during the time frame of this study. ${ }^{22}$ The ratings of $\mathrm{S} \& \mathrm{P}$ exist for all bonds in consideration. ${ }^{23}$

\footnotetext{
${ }^{21}$ As reported in the International Monetary Fund's Dissemination Standards Bulletin Board (DSBB), June 2002.

${ }^{22}$ The ratings in Table 2 are the common ratings of the Eurobond issues in the sample. A rating change might be anticipated when the country is put on credit watch. E.g. the first downgrade in the table was already anticipated since investors expected negative implications from S\&P putting Argentina on credit watch on 01 November 2000.

${ }^{23}$ For an in depth analysis of the statistical properties of sovereign credit ratings see Cruces (2001).
} 
Figure 5: three-year cumulative default probability and recovery ratio

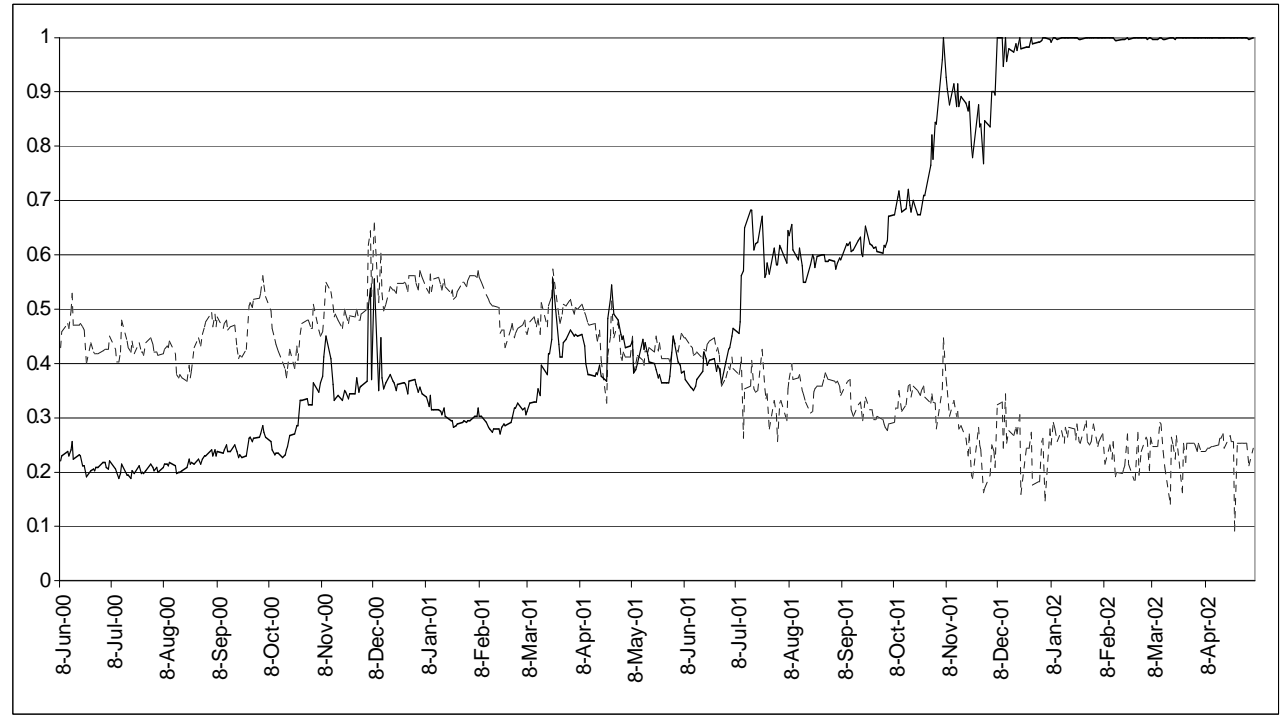

Course of the three-year cumulative risk neutral default probability (solid line) and the recovery ratio (dashed line) for the complete sample.

\section{Estimation results}

In the following, the results for daily parameter estimates throughout the whole sample are presented. For illustrative purposes, the cumulative default distribution for a time interval of three years from the observation date is calculated from the default parameter estimates. ${ }^{24}$ Figure 5 shows the threeyear cumulative default probability and the recovery ratio.

In 1999 Argentina slid into a recession and GDP shrank by $3.2 \%$ that year. This was also triggered by the Brazilian devaluation. Still, the default probability in July 2000 is as low as $20 \%$, shortly after Argentina promised the IMF to restore fiscal balance until 2003. This means that one could conclude from the risk neutral pricing model that the Republic of Argentina will default on a payment due in three years with a risk neutral probability of $20 \%$. The default risk is then creeping up throughout the sample and finally reaches the upper level of $100 \%$ at the beginning of December 2001, that is prior to the date the Argentine government officially declared default on external debt. The recovery ratio starts out at a level between 40 and 50 of a nominal of 100 and drops to a level below $40 \%$ in summer 2001. After

\footnotetext{
${ }^{24}$ This means, that the daily estimates of the parameters $\alpha$ and $\beta$ are used to calculate $\exp \left(-\exp \left(-\frac{3-\alpha}{\beta}\right)\right)$.
} 
default, a $20 \%$ to $30 \%$ recovery of face value is expected by the market participants.

The graph shows some peaks with characteristically high correlation between default probability and recovery ratio. Most of them can be justified by heavy market movements (as in the case of the peaks in November 2001) or - in some cases - by obviously mispriced quotes of single issues (as in the case of Arg06 around 08 December 2000). Over the whole sample, the three-year default probability and the recovery ratio have a covariance of -0.026 , which does not hint at a prevailing identification problem. Certainly, during periods of mainly invariate prices, the covariance is low but positive. ${ }^{25}$

Figure 6 shows the resulting estimates of the two parameters describing the Gumbel hazard function. The parameter $\alpha$ is the location parameter and serves to visualize after which period of time default was approximately seen as most probable in this risk neutral model. The result is striking in the sense that the curve obviously declines towards the date Argentina actually defaults.

The dashed line in Figure 6 represents the scale parameter $\beta$, which determines the standard deviation of the cumulative Gumbel density (see Section 2). Until bond prices trade very low, the scale parameter remains at a higher level. It is very obvious that during times of turbulent market movements $\beta$ goes up. This is the case, for instance, in spring 2001. After market disappointment about lower tax revenues than expected, a political crisis evolved. In the end, a shuffle of the cabinet brought Domingo Cavallo back into power. This period of uncertainty is reflected by very high values of $\beta$. After a new IMF deal was clinched in May, market sentiment calmed and spreads narrowed. ${ }^{26}$ This course of events is reflected in Figure 6 by a very high scale parameter and occasional slumps of the location parameter.

From the course of the default probability, one can identify periods of rather stable default probabilities followed by jumps. This divides the time frame into five periods. Table 3 states means, variances, and correlations for the different periods as well as for the whole sample. Mean values for $\alpha$ decline during the course of the periods. Except for the last period, the scale parameter $\beta$ remains high. The recovery ratio $\psi$ drops to a realistic

\footnotetext{
${ }^{25}$ For instance, from June to October 2000 , where prices trade very stable, the covariance is 0.001 .

${ }^{26}$ The deal ensured further help from the USD 40 billion loan package negotiated in December under the lead of the IMF. The deal was conditional on meeting the fiscal deficit target of USD 6.5 billion. At the end of April 2001 economy minister Cavallo admitted that Argentina will miss this target by about USD 4 billion.
} 
Figure 6: Location and scale parameter of the Gumbel hazard function

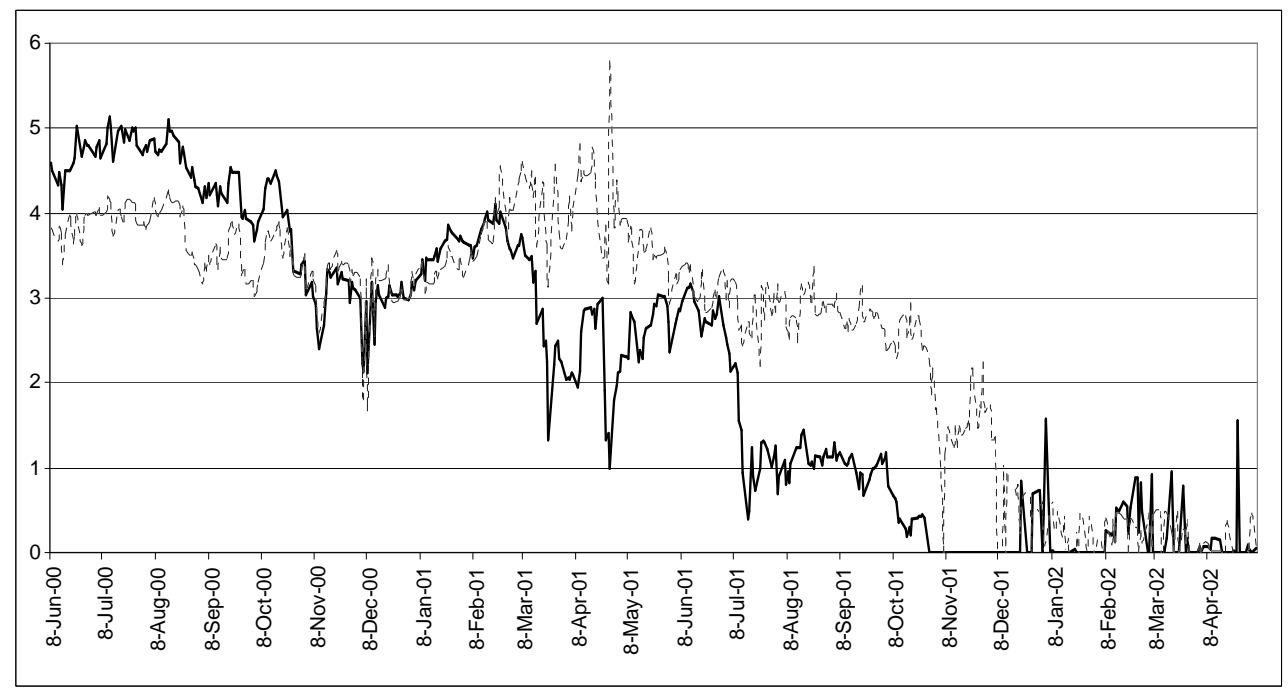

The location paramter $\alpha$ (bold solid line) indicates the time span in years after which the density of the hazard function shows its maximum. The scale parameter $\beta$ (dashed line) is proportional to the Gumbel density's standard deviation.

level of $25 \%$ in the fifth period. In all single periods the daily estimates of $\alpha$ and $\psi$ are negatively correlated. ${ }^{27}$

During the first period, in summer 2000, spreads came down in favor of Argentina. Hopes culminated in the new president Fernando de la Rua, who followed the Peronist Carlos Menem. The markets' perception of Argentina's country risk improved and Argentina successfully managed to place a number of new Eurobond issues. Together with the fact that the Brazil Real recovered again, this made the endurance of the Peso-Dollar peg more credible.

In the model, these circumstances are reflected by a mean pseudo default probability of $23 \%$ for a three-year horizon and a mean recovery rate of $44 \%$. The location parameter $\alpha$ suggests that a potential debt crisis was not expected in the near future. The default parameters $\alpha$ and $\beta$ both show low variances. The high values of $\alpha$ and $\beta$ together with their high correlation cause this model to behave more like a model using a constant hazard rate $\mu(t)=\lambda$ (see Equation 4). This finding indicates that market participants

\footnotetext{
${ }^{27}$ This is contrasting the high positive correlation in the total sample. It shows the distinctiveness of the different periods. Joining the periods two and three as well as four and five would also result in positive correlations between $\alpha$ and $\psi$ in each of the resulting subsamples.
} 
Table 3: Means, variances, and correlation matrices of the estimators

Total sample

\begin{tabular}{cccccc} 
& Mean & Variance & \multicolumn{3}{c}{ Correlation Matrix } \\
$\alpha$ & 2.19 & 2.91 & 1.00 & 0.74 & 0.80 \\
$\beta$ & 2.64 & 2.01 & & 1.00 & 0.72 \\
$\psi$ & 0.39 & 0.012 & & & 1.00
\end{tabular}

\begin{tabular}{|c|c|c|c|c|c|}
\hline \multicolumn{6}{|c|}{ Period 1 (08-Jun-2000 - 30-Oct-2000) } \\
\hline & Mean & Variance & \multicolumn{3}{|c|}{ Correlation Matrix } \\
\hline$\alpha$ & 4.48 & 0.17 & 1.00 & 0.87 & -0.64 \\
\hline$\beta$ & 3.75 & 0.10 & & 1.00 & -0.80 \\
\hline$\psi$ & 0.44 & 0.002 & & & 1.00 \\
\hline \multicolumn{6}{|c|}{ Period 2 (31-Oct-2000 - 23-Mar-2001) } \\
\hline & Mean & Variance & \multicolumn{3}{|c|}{ Correlation Matrix } \\
\hline$\alpha$ & 3.28 & 0.23 & 1.00 & 0.59 & -0.40 \\
\hline$\beta$ & 3.44 & 0.27 & & 1.00 & -0.74 \\
\hline$\psi$ & 0.52 & 0.002 & & & 1.00 \\
\hline \multicolumn{6}{|c|}{ Period 3 (26-Mar-2001 - 10-Jul-2001) } \\
\hline & Mean & Variance & \multicolumn{3}{|c|}{ Correlation Matrix } \\
\hline$\alpha$ & 2.53 & 0.19 & 1.00 & -0.36 & -0.38 \\
\hline$\beta$ & 3.65 & 0.32 & & 1.00 & 0.41 \\
\hline$\psi$ & 0.44 & 0.002 & & & 1.00 \\
\hline \multicolumn{6}{|c|}{ Period 4 (11-Jul-2001 - 26-Oct-2001) } \\
\hline & Mean & Variance & \multicolumn{3}{|c|}{ Correlation Matrix } \\
\hline$\alpha$ & 0.93 & 0.11 & 1.00 & 0.31 & -0.07 \\
\hline$\beta$ & 2.77 & 0.06 & & 1.00 & -0.16 \\
\hline$\psi$ & 0.34 & 0.001 & & & 1.00 \\
\hline \multicolumn{6}{|c|}{ Period 5 (29-Oct-2001 - 06-May-2002) } \\
\hline & Mean & Variance & \multicolumn{3}{|c|}{ Correlation Matrix } \\
\hline$\alpha$ & 0.14 & 0.09 & 1.00 & -0.19 & -0.65 \\
\hline$\beta$ & 0.53 & 0.38 & & 1.00 & 0.05 \\
\hline$\psi$ & 0.25 & 0.002 & & & 1.00 \\
\hline
\end{tabular}

Mean, variance, and correlation matrix of daily estimates of the location parameter $\alpha$, the scale parameter $\beta$, and the recovery ratio $\psi$. 
apply constant term spreads in standard pricing frameworks. ${ }^{28}$

In October, the country was shaken by the resignation of vice president Alvarez and by doubts about the government's capacity to enact the austerity plan. Beginning of November, Standard \& Poor's put Argentina on negative outlook and rumors originated by the former Argentine president Raul Alfonsin spread about the necessity of a moratorium.

This marks the transition to the second period. In the second period the cumulative three year default probability jumpes up to $34 \%$ due to Standard \& Poor's assigning a negative outlook to Agentina's double B rating. The peaks around 08 December 2000 stem from pricing inaccuracies of the Arg06 bond. Until February 2001 prices recovered since international lenders approved a USD 39.7 billion aid package by the end of December 2000, USD 13.7 billion of which were directly provided by the IMF. In the model, this is reflected by a very high level of the recovery ratio. In the first half of the period, default probability and recovery ratio rise in parallel, whereas in the second half, the default probability sinks and the recovery expectation remains stable.

In February 2001, the implied recovery ratio $\psi$ drops by around ten percentage points. This might reflect fears that the IMF deficit spending targets could not be met. Additionally, the Turkish Lira devaluation and political events in Turkey provoked contagion effects. In March 2001 finally, the implied default probability rises as the location parameter $\alpha$ drops. This can be associated with the political turmoils when president de la Rua called his cabinet to resign followed by a rating cut by S\&P on 26th March.

This is the beginning of the third period. During this period, the default probability and the recovery expectation seem to stabilize in Figure 5. Argentina succeeded in swapping debt to defer due payments of a total amount of USD 16 billion through $2005 .^{29}$ However, the mean of the location parameter $\alpha$ is now down at 2.5 during the third period, translating into a cumulative risk neutral default probability of $42 \%$ within three years. The average recovery ratio can be found at a level of about $44 \%$ moving slightly downwards throughout the sample. For the first time the correlation between $\alpha$ and $\beta$ is negative: $\beta$ begins to fall indicating that investors now have obtained a relatively sharp picture about what might happen to

\footnotetext{
${ }^{28}$ This conclusion can also be drawn from a bootstrapping analysis to yield the implied zero curve. For the first period, such an analysis shows that the implied zero curve is almost flat around a mean yield of $12.4 \%$. A relatively flat term structure can only be observed during the early stages of the sample.

${ }^{29}$ The peaks on 27 April 2001 in Figures 5 and 6 can be ascribed to single bond prices moving in opposite directions.
} 
Argentina in the near future. The $\mathrm{S} \& \mathrm{P}$ rating cut in May did not effect markets heavily. ${ }^{30}$

After 10 July 2001, prices - especially those of long term issues responded heavily to the assignment of a negative outlook for the S\&P single B rating which was followed by rating actions of Moody's and Fitch. The spread over U.S. Treasuries widened to more than 13 percentage points due to warnings of further rating cuts. This is the beginning of the fourth period.

The cumulative three-year default probability is now up at $62 \%$, which is reflected by an $\alpha$ of 0.93 and a very low mean scale measure of 2.77 . This period is marked by very stable parameter estimations, reflected by the extraordinary low variance level of the implied default parameters. This might origin from a stabilization of the situation in Argentina. In August 2001, the IMF increased its stand-by loan agreement and the pace of withdrawals from local accounts slowed down. However, the analysis shows that the recovery ratio follows a downward trend and has a mean of 0.34 in this period.

In October, the parameter estimations suggest another deterioration of the crisis. Reasons for this might be rumors about the quitting of economy minister Domingo Cavallo and the fear of a Peso devaluation. A devaluation would make debt obligations even more costly and could trigger an Argentine banking crisis.

Therefore, the fifth period starts about end of October. The default probability reaches 1 first on 06 November 2001, the day when Standard \& Poor's put Argentina's credit rating to "selective default". But on the following day, the announcement of a spending deal with the Argentine provinces raised hopes for immediate IMF help and the avoidance of bankruptcy, causing the default probability to drop again.

The location parameter is estimated to be zero almost throughout the entire fifth period. ${ }^{31}$ The implied cumulative default probability for a three year horizon is $97 \%$ on average. Since bonds were already rated "selective D" on 6th November, the S\&P default rating on 19 November 2001 did not come as a surprise. ${ }^{32}$ The only reaction observable in this model is the recovery ratio dropping well below $30 \%$ and remaining in a range between $20 \%$ and $30 \%$ for the rest of the sample.

\footnotetext{
${ }^{30}$ Since Argentina announced a debt swap just days before the rating cut, S\&P was criticized for this step and market participants refused to react to the rating change. The previous trading sessions had also been dominated by a bond market rally after a letter of intent with the IMF was signed on 04 May 2001.

${ }^{31}$ Deviations result from distorted prices since liquidity became very low after default.

${ }^{32}$ The Arg27 was rated D on 26 November 2001.
} 
The division into five periods marked by jumps in the implied cumulative default probability proves to be a solid framework for describing the Argentine sovereign debt crisis. In most cases, the transition to another period is accompanied by a rating cut by Standard \& Poor's. The location parameter of the extreme value distribution applied in this model gives a clear picture of the expected arrival time of default. The recovery ratio shows a persistent downward trend throughout the analyzed time period. The intuitively appealing empirical results underline the usefulness of the model applied in this article.

\section{Analysis of single issues}

This section compares the dirty market prices of single issues to their fitted values resulting from daily estimates in Section 5 . This offers valuable insight into the performance of the model introduced in Section 2.

Throughout the sample, the RMSE of daily estimates is as low as 0.05 most of the time. Increased pricing errors occur in July 2001 and during the volatile period after November 2001. Excessive root mean squared pricing errors are sometimes caused by single bonds which show extraordinary high price deviations. As already mentioned above, the Arg06 issue is not well suited by the model and causes some pricing error peaks. ${ }^{33}$ Beside the Arg06 issue, the Arg15 bond can be identified to have caused higher root mean squared errors, mostly due to illiquidity. ${ }^{34}$ The results presented in Section 5 therefore show robustness in the sense that excluding selected observations does not lead to different conclusions.

Taking the simple mean of the pricing error, calculated as dirty market price minus fitted model price, and its standard deviation, pricing failures from Table 4 can be compared between the different periods.

\footnotetext{
${ }^{33}$ This is the case, for instance, on 23 April 2001, 06 November 2001, and 20 December 2001. In all cases, the market price of the Arg06 bond is too high in relation to the model price. Excluding these observations leads to slightly different parameter estimates which delete some outlyers from Figure 5. For instance, this is the case on 06 November 2001, when the recovery ratio would change from $45 \%$ to $36 \%$ after excluding Arg06 from the sample for that day.

${ }^{34}$ For instance, in the second half of February 2002 the Arg09 was significantly overpriced sticking to a price of USD 35.67. Excluding these observations from the sample and recalculating the parameters during the period from 18 February 2002 to 28 February 2002 causes the RSME to drop by $43 \%$ on average. However, the overall picture of the parameter estimates does not change in a manner which would contradict the findings of Section 5. The mean value of $\alpha$ becomes 0.08 instead of 0.59 . The mean recovery ratio is slightly higher at $26 \%$ against $21 \%$ before.
} 
Table 4: Pricing errors during five periods

\begin{tabular}{|c|c|c|c|c|c|c|c|c|c|c|}
\hline \multicolumn{11}{|c|}{ Period 1 (08-Jun-2000 - 30-Oct-2000) } \\
\hline & Arg01 & Arg03 & Arg06 & Arg09 & Arg10 & Arg15 & $\operatorname{Arg} 17$ & Arg20 & $\operatorname{Arg} 27$ & RMSE \\
\hline Mean & 1.29 & -0.46 & -0.31 & -0.96 & -0.54 & 0.57 & 84 & .06 & 1.48 & 0.042 \\
\hline S.D. & 0.54 & 0.72 & 0.67 & 074 & 80 & 8 & 70 & 70 & 68 & 0.011 \\
\hline \multicolumn{11}{|c|}{ Period 2 (31-Oct-2000 - 23-Mar-2001) } \\
\hline & Arg01 & $\operatorname{Arg} 03$ & $\operatorname{Arg} 06$ & Arg09 & Arg10 & Ar & $\mathrm{Ar}$ & Arg20 & 27 & RMSE \\
\hline Mean & 1.60 & -0.70 & -0.40 & & & & & & & \\
\hline S.D. & 0.75 & 1.27 & 0.77 & 1.11 & & 0 . & $1 .($ & 0.99 & 7 & 0.012 \\
\hline \multicolumn{11}{|c|}{ Period 3 (26-Mar-2001 - 10-Jul-2001) } \\
\hline & & Arg03 & Arg06 & Arg09 & Árg10 & AI & 7 & Arg20 & 27 & RMSE \\
\hline Mear & & -0.27 & 1.17 & 8 & & -0.04 & & 0.84 & 5 & 0.043 \\
\hline S.D. & & 0.79 & 1.77 & 0.74 & 0.10 & 109 & & 1.06 & 0.58 & 0.016 \\
\hline \multicolumn{11}{|c|}{ Period 4 (11-Jul-2001 - 26-Oct-2001) } \\
\hline & & Arg03 & Arg06 & Arg09 & $\operatorname{Arg} 10$ & 5 & $\mathrm{Al}$ & 20 & $\operatorname{Arg} 27$ & RMSE \\
\hline & & -0.30 & 2.29 & -0.69 & & -0.83 & 0 . & -0.28 & 0.81 & 0.069 \\
\hline S.D. & & 0.46 & 1.62 & 1.02 & 0.98 & 0.85 & 1.26 & 2.06 & 1.03 & 0.027 \\
\hline \multicolumn{11}{|c|}{ Period 5 (29-Oct-2001 - 06-May-2002) } \\
\hline & & Arg03 & Arg06 & Arg09 & Arg10 & $\operatorname{Arg} 15$ & $\operatorname{Ar}$ & Arg20 & $\operatorname{Arg} 27$ & RMSE \\
\hline $\mathrm{Me}$ & & 0.12 & 1.93 & 0. & -0.26 & -1.32 & 0.70 & -0.81 & 0.39 & 0.159 \\
\hline S.D. & & 1.36 & 2.14 & 1.98 & 1.26 & 1.67 & 1.60 & 2.04 & 1.78 & 0.064 \\
\hline
\end{tabular}

The pricing error is defined as dirty market prices minus fitted model prices including accrued interest. The figures shown here are means and standard deviations from pricing errors calculated for each day using the daily estimates of Section 5. The RMSE shows the root mean squared error of the estimation. The Arg01 is only included until 19 February 2001 . 
Up to its maturity, the Arg01 bond is traded higher than the theoretical model value suggests. So does the Arg17 issue, which remains overpriced throughout the whole sample. Despite having the same coupon, the Arg10 bond is the only bond, which trades cheap on average for all periods. The Arg20 shows positive pricing errors through the first three periods and negative pricing errors during the periods of intensifying crisis symptoms. This evolvement is opposite to the Arg27 issue, which trades cheap during the first three periods and rich thereafter.

Despite the need of explaining single pricing errors in more depth, Table 4 does not suggest that the pricing errors show a certain pattern or significant biases with respect to price levels, maturities, or coupons.

Additionally, results can be compared to the analysis of Merrick (2001) who uses a slightly different model and applies it to a different time frame analyzing Argentine Eurobonds for contagion effects during the Russian default 1998. ${ }^{35}$ Comparing pricing errors of single issues, especially the long maturity issues prove to show almost similar pricing errors prior to default. ${ }^{36}$ The difference of pricing errors for shorter maturities could stem from the different approaches to modelling the bond price. The differences between these approaches have their strongest effect on payments in the near future.

The results from the single bond analysis clarifies that the model does not show significant biases with regard to general bond characteristics. In most cases, pricing errors do not remain constant throughout all periods. Nevertheless, no pattern can be recognized from the analysis. Therefore, an in-depth research of single issues with regard to related markets (such as the repurchase agreement market or the default swap market) could possibly offer more insight.

\section{Conclusion}

This paper utilizes three parameters to describe sovereign bond prices during the Argentine crisis 2001/2002 assuming risk neutrality. Building on the frameworks provided by Jarrow and Turnbull (1995) and Duffie and Singleton (1999), a pricing model is developed to estimate implied default parameters and recovery ratios simultaneously. Thereby, a hazard function using the Gumbel distribution is applied which is very helpful to illustrate the course of a debt crisis. To estimate the parameters, dirty market prices of

\footnotetext{
${ }^{35}$ In contrast to this analysis, Argentine bond prices did not drop below USD 70 in 1998.

${ }^{36}$ The sample of Merrick (2001) contains only five bonds, namely Arg01, Arg03, Arg06, $\operatorname{Arg} 17$, and Arg27.
} 
a cross section of bonds are compared to theoretical bond values. The recovery of face value (RFV) approach helps to avoid an identification problem. Given there is considerable default risk and the bonds in the sample show distinctive differences in duration, exact parameter estimates are gained. In most cases, samples containing bonds which trade at almost the same level do not sufficiently characterize the shape of the hazard function and are therefore not suitable to identify the parameters. Distortions can also result from very volatile prices or when liquidity is low.

Applying the model on a sample of nine Argentine Eurobonds throughout a time frame from June 2000 to May 2002, five different periods segregated by jumps in the implied risk neutral default probability can be separated. Most jumps are associated with rating downgrades by S\&P. The location parameter of the Gumbel distribution, indicating in which year from the reference date the density of the default probability term structure is at its maximum, drops each period by around one from five in the beginning to almost zero in November 2001. The course of the implied recovery ratio shows that investors assumed a recovery fraction of face value of $40 \%$ to $50 \%$ in the beginning. After the IMF and other international lenders approved a USD 40 billion aid package, the recovery ratio rises to well above $50 \%$ at the beginning of 2001. After default at the end of 2001 the level of the recovery ratio is well below $30 \%{ }^{37}$ Daily parameter estimates were used to calculate pricing errors of single bond issues. Pricing errors do not show certain patterns with regard to bond characteristics and therefore support the usefulness of the model.

\section{A The Gumbel distribution}

The Gumbel distribution,

$$
G(x)=\exp \left\{-\exp \left[-\frac{x-\alpha}{\beta}\right]\right\}, x \in \mathbb{R},
$$

is a special type of the general extreme value distribution. ${ }^{38}$ The use of the Gumbel distribution in this paper is motivated by the characteristic shape of its density, which is determined by two parameters, $\alpha$ and $\beta$.

\footnotetext{
${ }^{37}$ Latest news prove even this recovery ratio to be far too optimistic. In October 2003 Argentina specified its debt restructuring offer achieving a debt reduction of $75 \%$ on USD 94 billion nominal debt which results in even higher loss rates for investors.

${ }^{38}$ See Embrechts et al. (1999), p. 121; Coles (2001), pp. $45 f$.
} 
Figure 7: Gumbel distribution for different parameters
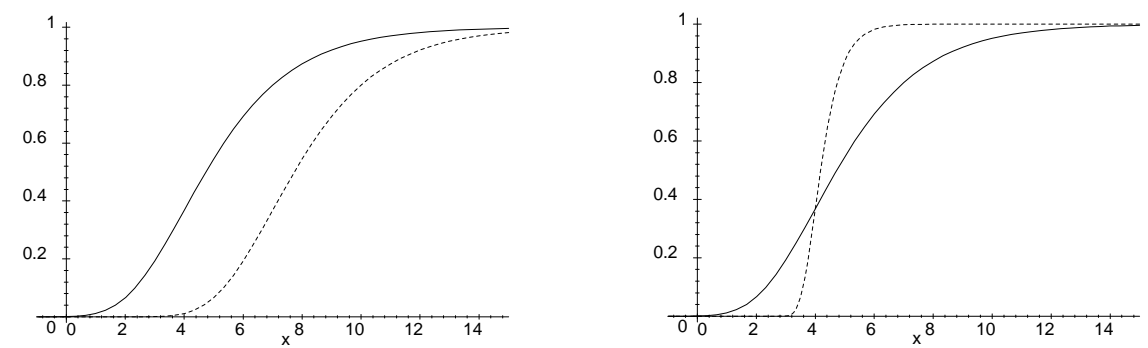

The graph on the left hand side shows the Gumbel distribution for two different values of $\alpha$, while $\beta$ is constant at 2. The solid line shows the distribution for $\alpha_{1}=4$ and the dotted line for $\alpha_{2}=7$. On the right hand side, $\alpha=4$ in both cases and $\beta$ varies. The solid line plots the distribution for $\beta_{1}=2$ and the dotted line for $\beta_{2}=0.5$.

Figure 7 illustrates the Gumbel distributions for some arbitrary parameters. From the distribution function $G$ follows the probability density function which is illustrated in Figure 8.

$$
g(x)=\frac{1}{\beta} e^{-(x-\alpha) / \beta} e^{-e^{-(x-\alpha) / \beta}}
$$

As can be seen in Figure 8, the location parameter $\alpha$ describes the mode of the density, whereas the shape parameter $\beta$ is proportional to the density's standard deviation. Thereby, each parameter determines a different characteristic of the distribution. For instance, a change of $\alpha$ leads only to a change in the location of the distribution function without affecting the shape of the function. This is a very convenient effect, especially for illustrative reasons. ${ }^{39}$

The values for the moments of the Gumbel distribution are:

$\begin{array}{lc}\text { Mean: } & \alpha+\gamma \beta \\ \text { Median: } & \alpha-\beta \ln (\ln (2)) \\ \text { Standard deviation: } & \frac{\beta \pi}{\sqrt{6}} \\ \text { Skewness: } & \frac{12 \sqrt{6} \zeta(3)}{\pi^{3}} \\ \text { Kurtosis: } & \frac{12}{5}\end{array}$

\footnotetext{
${ }^{39}$ The disadvantage is that for reasons of this study the range of the location parameter $\alpha$ has to be restricted to nonnegative values. However, as shown in Section 2, this caveat is easy to handle.
} 
Figure 8: Gumbel density for different parameters
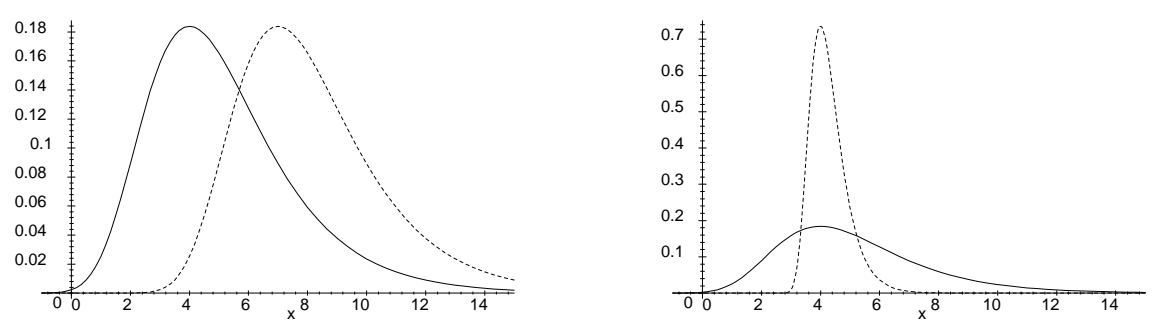

On the left hand side, the Gumbel density is plotted for different values for $\alpha$, while $\beta=2$. Again, the solid line shows the distribution for $\alpha_{1}=4$ and the dotted line for $\alpha_{2}=7$. The figure on the right hand side illustrates two distributions for $\alpha=4$. The solid line plots the density for $\beta_{1}=2$ and the dotted line for $\beta_{2}=0.5$.

where $\gamma \approx 0.5772$ is the Euler-Mascheroni constant, $\zeta(3) \approx 1.202$ is the Apéry's constant, and $\pi \approx 3.142$.

\section{References}

Bakshi, Gurdip, Dilip B. Madan and Frank X. Zhang (2001), Understanding the role of recovery in default risk models: empirical comparisons and implied recovery rates, Working paper, University of Maryland.

Bhanot, Karan (1998), 'Recovery and implied default in brady bonds', Journal of Fixed Income 8, 47-51.

Bielecki, Tomasz R. and Marek Rutkowski (2002), Credit Risk: Modeling, Valuation and Hedging, Springer Verlag, Berlin, Heidelberg, New York.

Black, Fisher and John C. Cox (1976), 'Valuing corporate securities: Some effects of bond indenture provisions', Journal of Finance 31, 351-367.

Claessens, Stijn and George Pennacchi (1996), 'Estimating the likelihood of mexican default from the market prices of brady bonds', Journal of Financial and Quantitative Analysis 31, 109-126.

Coles, Stuart (2001), An introduction to statistical modeling of extreme values, Springer Verlag, Berlin, Heidelberg, New York.

Cossin, Didier and Hugues Pirotte (2001), Advanced Credit Risk Analysis: Financial Approaches and Mathematical Models to Asses, Price, and Manage Credit Risk, John Wiley \& Sons, New York et al. 
Duffie, Darrell and Kenneth J. Singleton (1999), 'Modeling term structures of defaultable bonds', The Review of Financial Studies 12, 687-720.

Duffie, Darrell, Lasse Heje Pedersen and Kenneth J. Singleton (2003), 'Modeling sovereign yield spreads: A case study of russian debt', Journal of Finance 58, 119-159.

Eaton, Jonathan and Mark Gersovitz (1981), 'Debt with potential repudiation: Theoretical and empirical analysis', Review of Economic Studies 48, 289-309.

Embrechts, Paul, Claudia Klüppelberg and Thomas Mikosch (1999), Modelling extremal events, Springer Verlag, Berlin, Heidelberg, New York.

Fischer, Edwin O., Robert Heinkel and Josef Zechner (1989), 'Dynamic capital structure choice: Theory and tests', Journal of Finance 44, 1940.

Fons, Jerome S. (1987), 'The default premium and corporate bond experience', Journal of Finance 42, 81-97.

Ghosal, Sayatan and Marcus Miller (2002), Co-ordination failure, moral hazard and sovereign bankruptcy procedures, Working paper, University of Warwick.

Gibson, A. Ron and Suresh M. Sundaresan (1999), A model of sovereign borrowing and sovereign yield spreads, Working paper, HEC.

Gumbel, Emil Julius (1958), Statistics of Extremes, Columbia University Press, New York.

Hull, John C. and Alan White (1995), 'The impact of default risk on the prices of options and other derivative securities', Journal of Banking and Finance 19, 299-322.

Jarrow, Robert A., David Lando and Stuart M. Turnbull (1997), 'A markov model for the term structure of credit spreads', The Review of Financial Studies 10, 481-523.

Jarrow, Robert A. and Stuart M. Turnbull (1995), 'Pricing derivatives on financial securities subject to credit risk', Journal of Finance 50, 53-85.

Keswani, Aneel (2000), Estimating a risky term structure of brady bonds, Working paper, Lancaster University. 
Lando, David (1998), 'On cox processes and credit risky securities', Review of Derivatives Research 2, 99-120.

Longstaff, Francis A. and Eduardo S. Schwartz (1995), 'A simple approach to valuing risky fixed and floating rate debt', Journal of Finance 50, 789819 .

Merrick, John J. (2001), 'Crisis dynamics of implied default recovery ratios: Evidence from russia and argentina', Journal of Banking and Finance 25, 1921-1939.

Merton, Robert C. (1974), 'On the pricing of corporate debt: The risk structur of interest rates', Journal of Finance 29, 449-470. 